\section{SCALO: A program to perform Guttman scaling analysis on the Apple II microcomputer}

\author{
ANDREW R. GILPIN \\ University of Northern Iowa, Cedar Falls, Iowa
}

The purpose of the program SCALO is to perform Guttman (1950) scalogram analysis on a set of up to 100 test items with dichotomous responses. The program computes the reproducibility index ("REP"), a statistical test of the significance of the index, and a variety of measures of test reliability.

Requirements. The program is written in APPLESOFT BASIC and is intended for use on a $48 \mathrm{~K}$ Apple II microcomputer, although conversion to similar dialects of MICROSOFT BASIC would be fairly straightforward. Depending on the input mode selected ("DATA" statements or disk files), the number of subjects is constrained only by the amount of core memory or the potential file size, respectively; thus, the program can be used to analyze fairly large data sets. The program itself is relatively large, consisting of 278 lines of BASIC code.

Input/output options. There are two modes of input: (1) "DATA" statements incorporated in the program itself prior to run time, and (2) data previously stored in a sequential data file. A missing data option is avail-

The author's mailing address is: Department of Psychology, University of Northern Iowa, Cedar Falls, Iowa 50614. able. There are also two modes for output: (1) the screen (in which case scrolling is periodically interrupted) and (2) a printer connected to any slot (port).

Methodology. The program SCALO scans the data twice. On the first pass, it computes the difficulty index for each of the items and prints out the indexes in the original item order, after sorting by difficulty. Several measures of oddeven reliability are also computed: Pearson coefficient, Spearman-Brown, KuderRichardson No. 20, and Guttman (see Helmstadter, 1964). On the second pass, the program computes Guttman's (1950) "REP" index, as well as the chance REP and two chi-square tests of the significance of the observed REP (Hofmann, 1979).

Availability. A program listing and user's notes are available without charge by writing Andrew R. Gilpin, Department of Psychology, University of Northern Iowa, Cedar Falls, Iowa 50614. Copies on diskette (DOS 3.3) may be obtained by sending a blank diskette plus $\$ 2$ (to cover postage and handling costs) to the same address.

\section{RITERENCES}

Gutrman, L. The basis for scalogram analysis. In S. A. Stouffer, L. Guttman, E. A. Suchman, P. F. Lazersfeld, S. A. Star, \& J. A. Clausen (Eds.), Measurement and prediction. Princeton, N.J: Princeton University Press, 1950.

Helmgtadter, G. C. Principles of psychological measurement. New York: Appleton-Century-Crofts, 1964.

Hormann, R. J. On testing a Quttman scale for significance. Educational and Psychological Measurement, 1979, 39, $297-301$.

(Manuscript accepted for publication September 23, 1983.) 